
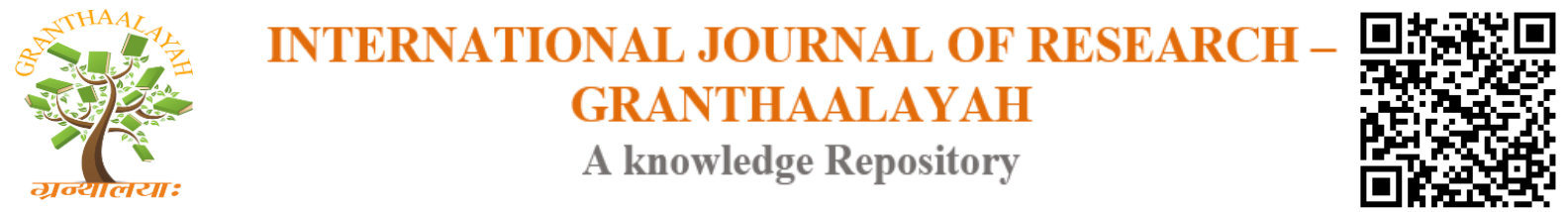

Management

\title{
TOTAL QUALITY MANAGEMENT IN B.ED COLLEGE
}

\author{
Priti Sivaramakrishan $* 1$ \\ ${ }^{* 1}$ St. Xavier's Institute of Education, INDIA
}

DOI: https://doi.org/10.29121/granthaalayah.v4.i8(SE).2016.2583

\begin{abstract}
The aim of the present study was to investigate the perception of B.Ed student teachers towards Total Quality Management (TQM) in Teacher Training Colleges. The study aims to evaluate how well the college functions in the transaction of imparting the teaching learning process. The study was conducted on 68 B.Ed student teachers from one of the teacher training colleges of Mumbai University. The data was analyzed using percent mean method. The results of the study showed that most of the dimensions of quality control ranged between $60 \%$ to $75 \%$ which suggests that the said college has room for improvement on its services.
\end{abstract}

Keywords:

Education, B.Ed, College Students, Teacher \& Learning Process.

Cite This Article: Priti Sivaramakrishan, "TOTAL QUALITY MANAGEMENT IN B.ED COLLEGE", International Journal of Research - Granthaalayah, Vol. 4, No. 8: SE(2016): 27-35.

\section{INTRODUCTION}

Quality has been an important aspect of any Industry be it service industry or a manufacturing industry. The word quality denotes investigation for the better. To determine success and failure in every aspect investigation is necessary. Quality is a very relative term. Quality in education is a matter of great quest and concern for institutions. According to Yeo (2009) 'Quality' means "to meet or exceed the expectations of customers". According to Idrus (1996), "what quality has done basically is shifted the way organizations and their people think about themselves and about all the things that impact on them". Quality in higher education is a multidimensional concept which includes all related function and activities that form part of academic life in a University system.

A teacher education institution fall within the purview of the service sector. Teacher education institutions need to define and determine the quality of service it provides. The origin of Total Quality Management began in the Japanese industry in the 1950's and became steadily more popular in the West since the early 1980's. Total Quality is a description of the culture, attitude and organization of a company that aims to provide, and continues to provide, its customers with 
products and services that satisfy their needs. The culture requires quality in all aspects of the company's operations, with things being done right the first time, every time and defects and waste eradicated from operations. Total Quality Management aims to transform the organization through progressive changes in attitudes, practices, structures and systems. Of the many approaches to Quality,TQM is the most reliable and unique method to track the progress and assure of quality.TQM has been tired in many educational institutions with impressive results (Sallis, 1993). TQM is an integrated organizational effort designed to improve quality at every level. The philosophy of TQM has impacts not only on the organization but also one's life. TQM is about meeting quality expectations as defined by the customer which is also called as customer-defined quality. TQM offers a vehicle for schools and colleges to manage themselves effectively in a time of rapid change and retain a clear focus on the essential and dominant purpose of education (Rao, 2003). According to Isani and Vir, (2005) quality should be assessed by taking into consideration the quality of students, teachers, infrastructure student support services, curricula assessment and resources. According to Mukhopadhyay (2005) the most sensitive creators on earth are human beings and therefore to judge quality in education is a enormous challenge

\section{DEMING'S - TOTAL QUALITY MANAGEMENT PRACTICES}

Total Quality Management (TQM) is a management approach to long-term success through customer satisfaction. In a TQM effort, all members of an organization participate in improving processes, products, services and the culture in which they work. A core concept in implementing TQM is Deming's 14 points, a set of management practices to help companies increase their quality and productivity:

1) Create constancy of purpose for improving products and services.

2) Adopt the new philosophy.

3) Cease dependence on inspection to achieve quality.

4) End the practice of awarding business on price alone; instead, minimize total cost by working with a single supplier.

5) Improve constantly and forever every process for planning, production and service.

6) Institute training on the job.

7) Adopt and institute leadership.

8) Drive out fear.

9) Break down barriers between staff areas.

10) Eliminate slogans, exhortations and targets for the workforce.

11) Eliminate numerical quotas for the workforce and numerical goals for management.

12) Remove barriers that rob people of pride of workmanship, and eliminate the annual rating or merit system.

13) Institute a vigorous program of education and self-improvement for everyone.

14) Put everybody in the company to work accomplishing the transformation.

Education has long been undertaken within groups and has been viewed as an important cultural transmission process (Singleton, 1974). A teacher training college consist of internal and external stakeholders. The report of Indian Education Commission (1964-66) states, "The destiny of India is being shaped in classrooms. The most important and urgent reform needed in education is to transform it, to endeavor to relate it to the life, needs and aspirations of the 
people, and thereby make it a powerful instrument of social change. The reforms in teacher education are necessary to achieve national goals. For this purpose, education should be developed so as to increase productivity, achieve social and national integration, strengthen democracy, accelerate the process of modernization and cultivate social, moral and spiritual values. According to (Coate, 1990a) "The very existence of any Institute is students" To provide the best service to its customer is the aim of any industry be in product based or service based. As Zairi (1995, p.30) states, it is ultimately students who should measure and judge the quality of services provided by the institute. According to (Hubbard, 1994b) "in the classroom, the students along with the instructor are 'suppliers' who produce a 'product' (knowledge) that future 'customers' (employers or graduate schools) will evaluate" .

\section{TOTAL QUALITY MANAGEMENT AND SHE WHART CYCLE}

She Whart Ccle, is a basic part of a TQM process. Also known as the Deming Cycle or Shewhart Cycle which is circular in nature which means improvement is continuous and is a never -ending process.

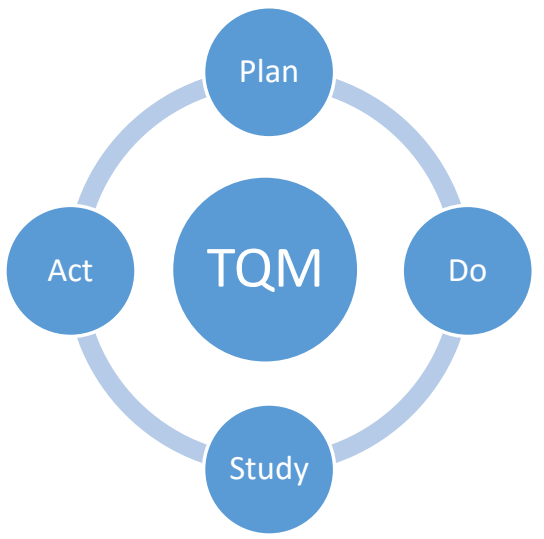

- Plan: Identify an opportunity and plan for change.

- Do: Implement the change on a small scale.

- Study: Use data to analyze the results of the change and determine whether it made a difference.

- Act: If the change was successful, implement it on a wider scale and continuously assess your results. If the change did not work, begin the cycle again.

The Schewart cycle helps to bring changes by evaluating the process and repeating the cycle to provide effective and better services to none other than its students. According to Fitzgerald (2004) Total quality management helps to serve its primary customers, students and employers in the best possible manner.

The Increasing demand for the services of these institutions makes the stakeholders of these institutions look for goods and services, to be of best quality and best price. Achievement of national goals is through Educational development. Teacher education has a significant role to play in maintaining the quality of education. Quality management is not an overnight process and it is not the product of a single hand for the realization of national goals. Elton (1992) suggests that quality enhancement focuses on quality E's empowerment, enthusiasm, expertise and excellence. 
As students are viewed as an integral part of the learning process (Wiklund et al., 2003), this type of evaluation tends to be more formative in nature and therefore more likely to lead to continual quality improvement efforts.

The aim of this paper is to discuss the mechanism of applying total quality management, in order to achieve the goals of educational institutions in (internal \& external environment). And find out the perception of the student teacher's towards quality of service provided by the Institution.

\section{OBJECTIVES OF THE STUDY}

- To study the perception of B.Ed students teachers towards total quality management.

\section{SAMPLE OF THE STUDY}

Stratified random sampling technique was used to collect the data from 68 teacher educators from one of the teacher training college in Mumbai.

\section{METHODOLOGY}

The research was descriptive research. Total Quality Management inventory by Dr. KishoriMiestry (2011) was used to find the perception of B.Ed student teachers. The reliability of the tool by split half and Cronbach alpha were 0.86 and 0.82 respectively and the tool was validated by a list of experts. Percent mean was used to find out the perception of B.Ed student teachers on the nine dimensions of total quality management.

\section{OPERATIONAL DEFINITIONS OF THE DIMENSIONS OF THE TOOL ON TOTAL QUALITY MANAGEMENT}

Total Quality Management:- is an ongoing process which educational managers' use, to enable everyone in the college to continuously improve their abilities so as to meet and exceed internal and external customer expectations. It is also referred to as continuous quality improvement of college.

\section{OPERATIONAL DEFINITIONS OF THE DIMENSIONS OF THE STUDY}

\section{1) Human Resource Management}

Human Resource Management (HRM) includes perception of the individuals (students and teachers) towards admission of students in a college, selection and appointment of teachers, development of students and the staff, and also efforts made by the institution to motivate them in their academic responsibilities and evaluate their work and recognize it.

\section{2) Operating Procedure}

Operating procedure involves the perception of the individual about the organization in bringing efforts about qualitative improvement through various rules and regulations in the academic and administrative functioning. 


\section{3) Quality Policy}

is the perception of the individual (teachers and students) about quality polices, involves setting up and implementing basic principles, guidelines and use of action plan by the management/ college to achieve the long term goals and short terms goals of the Institution.

\section{4) Services of Suppliers}

is the perception of the individual towards the work done by the Principal and Teachers towards the achievement of the goals of the Institution

\section{5) Technology Utilization}

Technology utilization means the perception about the appropriate use of computers, internet and technological devices to bring about qualitative improvement in the day-to-day functioning of the Institution.

\section{6) Training}

is the perception about the efforts put in by the institution in order to impart knowledge about the concept of Total Quality Management, and the ability, skills related to it, and bringing about changes in the attitude and behaviors of the students and teachers is referred to as training.

\section{7) Quality Culture}

Quality Culture refers to the perceived pattern of human habits, beliefs and behavior concerning quality.

\section{8) Quality Information System}

refers to the perception of the individual about maintaining information about the various components of quality and make available the information and provides information to those people who require information about the institute or college. Statements 116-128

\section{RESULTS}

Percent Mean of the Nine Dimensions of Total Quality Management

\begin{tabular}{|l|l|l|}
\hline Sr. No & Dimension & Percent Mean \\
\hline 1. & Human Resource Management & 3.3 \\
\hline 2. & Operating Procedure & 3.8 \\
\hline 3. & Quality Policy & 3.1 \\
\hline 4. & Services of Suppliers & 2.1 \\
\hline 5. & Technology Utilization & 2.2 \\
\hline 6. & Training & 3.5 \\
\hline 7. & Quality Culture & 2.4 \\
\hline 8. & Quality Information System & 3.8 \\
\hline
\end{tabular}




\section{INTERPRETATION}

The table clearly shows that percent mean for Operating Procedure and Quality Information System are in the range of 3.5-4\%. Human resource management, Quality Policy, and Training are in the range of 3.1-3.5\%. Services of Suppliers and Technology Utilization have the least percent mean score of $2.1 \%$ and $2.2 \%$ respectively.

\section{DISCUSSION AND CONCLUSION}

The Operating Procedure has scored highest percentage of 3.8. The admission procedures of the college is as per the University Norms where criteria for selection and admission of students is clearly communicated to the students. Transparency exists in the functioning, through planning in the conduct of the activities. The vision and mission statement of the institute is clearly communicated to the student teachers which ensures that internal and external stakeholders work in alignment with the vision and the mission of the institute.

\section{QUALITY INFORMATION SYSTEM}

\section{Quality Information system scored 3.8\%}

The quality information system is well in place with updated website and email address for the students to access. The institute regularly updates its website with the events and happenings of the college for the benefit of present student teachers and as well as alumni.

Training on quality scored $3.5 \%$. Student teachers are provided training on quality where teachers prepare students to be more committed and responsible towards quality. Timely decisions, brainstorming sessions, leadership programmes, are the few measures which ensures training on quality According to Neha Parekh (2013) every school should specifically equip its students to understand and use TQM.

Human Resource Management has scored 3.3\%. It was found through observation that the Institute manages its human resources well by forming different subgroups and arranging and organizing programmes like club activities, community work, guidance programmes which ensures human resource is well taken care off. The students are motivated by giving appropriate feedback, providing opportunities to students to participate in intercollegiate competitions. According to Dahlgard et al (1995) Quality culture is inclusive of products and services which deals with the preparation, development and training of teachers. The Organizations focus and strive to see that the human resources are well motivated and taken care of.

The quality policy is $3.1 \%$. The institute has a quality committee in place which ensures issues are addressed and quality decisions are implemented for continuous progress of the institute. Students are the backbone of the institute and therefore the needs and expectations of the students are well served. The institute has a grievance mechanism in place, for effective communication and to provide solutions to the student's grievances. According to Babbar (1995) commitment, honesty, openness and high ethics are very much essential to follow TQM. Teacher's should explore and be open to new ideas and apply TQM elements to one's own teaching. Adopting and applying TQM the organization is placing itself in the position of being 
constantly open to and striving towards new learning. According to Blades (1995) in order to implement and practice quality management's commitment is very essential. As the two ways process of communication helps the organization be aware of the expectations of the customers and make the customers know what expectations would be met by the organization. According to Blades (1995) commitment and communication are important requirements for quality.

Quality Culture has scored a percentage of $2.4 \%$. The institute believes in a culture of progress by undertaking small and regular changes to improve quality. The practice of the institute is to identify the needs of the institute and satisfy them. The motto of the college is to improve quality by finding out creative and innovative ways to solve college grievances. Elmut et al., (1996) found that total quality management helps to achieve organizational effectiveness by improving the participant' morale, productivity and adaptability to environmental changes.

\section{Technology Utilization}

Technology utilization scored $2.2 \%$. The student teachers need to be allowed to use technology services i.e., computer and internet facilities. The student teachers should be allowed and encouraged to use online publishing articles from the website.

\section{Services of Suppliers}

Services of the suppliers scored $2.1 \%$. The services of suppliers needs to improve in terms of teaching, simplifying the language during delivery of content. The institute also needs to focus on providing remedial teaching for the student teachers and persuading students to learn independently. The teachers of the institute are to focus on trying to build and enhance the personality of the student teachers. Raju et al., (1994) defined that quality of the course is determined by the satisfaction provided to the students in the form of support services. He also opined that ensuring satisfaction would help in improving higher education and enhancing student learning experience and serve as an instrument and making the higher education adjust and adapt to the tougher economic reality. According to Manivannan, M.; Premila, K.S(2009) opined that teacher education institutions should possess skilled teachers to produce students with versatile personality.

\section{CONCLUSION}

Although the total scoring is above the mean, the Institute is in the process of progressing towards achieving the highest score on each dimension. To conclude it can be said that the Institution is leaving no stone unturned to improvise and assure quality. As suggested by Suzana et.al. Quality must be consciously managed in order to satisfy quality demands. Application of Total Quality Management in education will give better results in all fields of the process of education as said by Mehrotra (2006) who suggests that TQM principles can be helpful for the working at educational institutes. According to Akhtar (2000) the philosophy of TQM is a participatory philosophy which can be achieved only through collaborative efforts of the members of the educational organization. The quality of higher education in India is one of the issues which a developing country like India needs to improve and enhance similar to the International Standards. TQM if consciously followed and implemented by the teacher training Institutes will enable the institutes to recognize their shortcomings and strengths. Teacher 
training institutes will be able to produce competent teachers who would be the striking force to build the nation builders of India.

\section{REFERENCES}

[1] Ali, N. A. \&Zairi, M. (2005) Service Quality in Higher Education. Bradford University School of Management, Bradford.

[2] Babbar Sunil 1995 Applying TQM to Educational Instruction, International journal of public sector management vol 8 No, 7, 1995,MCB University press USA.

[3] Babbar, S. (1995), "Applying Total Quality Management to Educational Instruction: A Case Study from a US Public University”, International Journal of Public Sector Management, Vol.8, No. 7, pp. 35-55.

[4] Blades, M. (1995).Development of a Simple Model for Analysis of Quality. Training of Quality, 3(l), 9-13. http://dx.doi.org/10.1108/09684879510082201

[5] Coate LE (1990) "TQM at Oregon State University”, J. Quality and Participation, 1990a(12): 90-101.

[6] Dahlgard et al (1995) has defined Quality a" An educational culture characterized by increased customer satisfaction through continuous improvements in which all employees and students actively participate.

[7] Elton, L. (1992) Quality Enhancement and Academic Professionalism. The New Academic, 1(2), 3-5.

[8] Fitzgerald, R. (2004) Total quality management in education. Minuteman career and technical high school. Retrieved from: http://www.minuteman.org/topics/tqm.htmld

[9] Golden, S. A. R. (2011). Problems and Prospectus of Distance Learning. Bharathidhasan University, 343, 344.

[10] Hubbard, D.L. (1994), "Can Higher Education Learn from Factories?”, Quality Progress, Vol.27, No.5, pp.93-97.

[11] Idrus, N. (1996), “Towards Total Quality Management in Academia”, Quality Assurance in Education, Vol.4, No. 3, pp. 34-40.

[12] Isani, U. A. G. and M. L.Virk. 2005.Higher Education in Pakistan: A Historical and Futuristic Perspective.National Book Foundation. Islamabad, Pakistan. P.232 -33

[13] M.Kishori, (2011) A Study of the Perception of Students and Teachers towards Total Quality Management in Higher Education Institutions in the district ofRatnagiri and Sindhudurg.

[14] Manivannan, M.; Premila, K. S(2009). Application of Principles of Total Quality Management (TQM) in Teacher Education Institutions Journal of College Teaching \& Learning, v6 n6 P77-88 Oct 2009

[15] Mukhopadhyay, M.( 2005).Total Quality Management in Education. Saga Publications Ltd. New Delhi, India.

[16] Regi, S. B., \& Golden, S. A. R. (2014). A Study On Educational Loan Availed By Students In Trichy City. JOURNAL OF INTERNATIONAL ACADEMIC RESEARCH FOR MULTIDISCIPLINARY (JIARM), 2(1).

[17] Parekh N (2013) Total Quality Management - A Must in Education Variorum MultiDisciplinary e-Research Journal Vol.,-04, Issue-I, August 2013. 
[18] Raju, R. Rajendran, G. and Sakthivel, P.B. (1994), "Total Quality Management Implementation in Higher Education Institutions, The TQM Magazine, Vol. 11, No. 5, pp. 211-218.

[19] Rao, V. K. 2003. Quality Education.S.B. Nangia, New Delhi, India.pp. 2, 16-17, 19. 26, 37.

[20] Singleton J (1974) 'Implications of education as a cultural transmission', in Spindler, G.D. (Ed.), Education and Cultural Process: Toward an Anthropology of Education, Holt, Rinehart and Winston, New York, NY, 26-38.

[21] Wiklund, H., Klefso, B., Wiklund, P., and Edvardsson, B. (2003), Innovation and TQM in Swedish Higher Education Institutions Possibilities and Pitfalls, The TQM Magazine, 15 (2), pp. $97-107$.

[22] Yeo, R.K., (2009), Service quality ideals in a competitive tertiary environment, International Journal of Educational Research, Vol.48, pp. 62-76

[23] Website: http://hdl.handle.net/10603/21184 